\title{
The metaethical dilemma of epistemic democracy
}

\author{
Christoph Schamberger (D) \\ Humboldt University of Berlin, Department of Philosophy, Unter den Linden 6, 10099 Berlin, Germany; \\ University of Erfurt, Department of Philosophy, Nordhäuser Straße 63, 99089 Erfurt, Germany \\ Email: christoph.schamberger@web.de
}

(Received 30 July 2020; revised 28 September 2021; accepted 4 October 2021; first published online 27 December 2021)

\begin{abstract}
Epistemic democracy aims to show, often by appeal to the Condorcet Jury Theorem, that democracy has a high chance of reaching correct decisions. It has been argued that epistemic democracy is compatible with various metaethical accounts, such as moral realism, conventionalism and majoritarianism. This paper casts doubt on that thesis and reveals the following metaethical dilemma: if we adopt moral realism, it is doubtful that voters are, on average, more than 0.5 likely to track moral facts and identify the correct alternative. By contrast, if we adopt conventionalism or majoritarianism, we cannot expect that voters are both competent and sincere. Either way, the conditions for the application of Condorcet's theorem are not met.
\end{abstract}

Keywords: Epistemic democracy; Condorcet Jury Theorem; social choice; moral realism; disagreement

\section{Introduction}

Epistemic theories of democracy aim to show that democracy works epistemically better than any other form of government, having a high chance, and indeed the highest chance, of reaching correct, right, or true decisions. At the same time, proponents of these theories, which are often grouped under the paradigm of epistemic democracy, usually avoid metaethical commitments and say little about what they mean by a correct, right, or true decision. I suspect that this metaethical abstinence hides a dilemma that becomes obvious when we spell out the consequences of different metaethical conceptions with respect to epistemic democracy.

In their recent monograph An Epistemic Theory of Democracy, Goodin and Spiekermann (2018; reviewed in this journal by Bright 2019) become the first epistemic democrats to delve somewhat deeper into traditional metaethical questions, devoting two sections of their impressive book to such matters (Goodin and 
Spiekermann 2018: 38-45). ${ }^{1}$ Their 'principal focus' is actually 'on common or garden truths of the sorts we bump into in science and when negotiating our way in the world' (Goodin and Spiekermann 2018: 11). However, it is not the main task of politics to find out such truths. Scientific experts are most qualified to answer questions about empirical facts such as the extent of climate change or the macroeconomic effects of proposed fiscal policies, and in most cases, it is better to defer to them. By contrast, the legislators' main task is to decide about laws and regulations. In doing so, they have to consider both questions about empirical facts and questions about moral values and norms. Democracy can make a claim to outperform all other forms of government if it attains the highest rate of correct decisions. So, Goodin and Spiekermann rightly turn to face the metaethical question of what makes political decisions correct. (They generally do not distinguish between the predicates 'correct', 'right', and 'true'. I will follow them in usually applying the adjective 'correct' to political decisions.)

All epistemic theories of democracy require a procedure-independent standard of correctness for political decisions that is defined prior to the decision procedure; that is, such a standard is not fulfilled simply by the fact that a decision is being reached in compliance with particular procedural rules. According to Goodin and Spiekermann, at least three metaethical accounts provide such a standard and are at the same time compatible with epistemic theories of democracy: moral realism, moral conventionalism, and moral majoritarianism (Goodin and Spiekermann 2018: 38-42). ${ }^{2}$ I conjecture that these accounts raise problems for all epistemic theories of democracy. However, I shall confine myself in this article to aggregative approaches to epistemic democracy based on the Condorcet Jury Theorem (CJT), which will be explicated in the next section. Goodin and Spiekermann's theory also rests on the CJT. While they do not explicitly commit themselves to either realism, conventionalism, or majoritarianism, they 'are inclined to think that any of them (or any combination of them) would suffice to establish the relevance of the CJT for politics' (Goodin and Spiekermann 2018: 38). Other epistemic democrats reject the application of the CJT to politics; instead, they stress the epistemic value and truth-conduciveness of democratic deliberation (Estlund 2008: Ch. 12; Landemore 2017; Estlund and Landemore 2018). This article does not target these deliberative approaches to epistemic democracy but refers only to aggregative approaches based on the CJT.

My aim is to reveal that the aggregative approaches are faced with a metaethical dilemma. Its first horn: if we adopt moral realism, it is doubtful that voters are, on average, competent - that is, more than 0.5 likely - to track moral facts and identify the correct alternative. The second horn: if we adopt moral conventionalism or moral majoritarianism, we cannot expect that voters are both competent and sincere. Either way, the conditions for the application of the CJT are not met.

\footnotetext{
${ }^{1}$ This is not to say that other epistemic democrats have not written about metaethical issues. For instance, Estlund (1993, 2008: Ch. 2, 2012) analyses the role of truth in democracy and liberal political philosophy, but he discusses traditional metaethical accounts only in passing.

${ }^{2}$ The authors add that one might restrict the scope of an epistemic theory of democracy to questions of fact, instead of committing oneself to any metaethical account. However, this 'moral separability' presupposes that one can distinguish sharply between questions of fact and questions of value, which turns out to be unfeasible in practice (Goodin and Spiekermann 2018: 40-41).
} 
The dilemma is actually a trilemma, but I will approach conventionalism and majoritarianism simultaneously.

After some brief remarks in the next section about the methodological framework surrounding the CJT, I will address the horns of the metaethical dilemma in turn. My focus will be on the first horn concerning moral realism (sections 3 and 4), whereas conventionalism and majoritarianism can be dealt with rather briefly (section 5).

\section{The Condorcet Jury Theorem (CJT)}

The classical version of the CJT states that under certain conditions the probability of a majority of voters reaching a correct decision converges to 1 as the number of voters rises (Black 1958: 164-165; Grofman 1975: 99-101). ${ }^{3}$ One of these conditions requires that voters are competent with respect to a given decision. In binary choices, where voters have to choose between exactly two alternatives, they are regarded as competent if and only if their belief about the correct alternative is more than 0.5 likely to be true. Typical examples of binary choices are elections between two candidates for a political office, referenda in which the whole electorate is invited to vote on whether or not to accept a proposal, and parliamentary votes on whether or not to adopt a bill. (Arguably, there is always the third alternative of abstention from voting, but I will ignore it to simplify matters.) It is further required that voter competence is homogeneous; that is, all voters have to have exactly the same competence with respect to a given decision. In addition, the voters' beliefs about what is the correct decision have to be independent of one another's. More precisely, they have to be independent conditional on the state of the world; that is, they may depend only on the state of the world. Finally, the persons have to express their opinions in good faith and vote sincerely for what they believe to be the correct alternative; in particular, they must not vote strategically (Goodin and Spiekermann 2018: 17-19).

These conditions for the application of the classical CJT are blatantly unrealistic. Beginning with Rawls (1999: 314-315, initially published in 1971), the independence assumption became the focus of criticism for the simple reason that voters share information and influence each other in the course of public and private discussions. It is also doubtful whether voters decide independently from the influence of mass media and social media (Anderson 2006: 11-12). Even epistemic democrats have rejected the independence assumption by noting that voters are often influenced by common causes such as shared evidence. However, the independence condition can be relaxed. To employ the CJT, votes must not be highly correlated, but they may be correlated to some degree (Ladha 1992: 625630; Kaniovski 2010: 460-646; Pivato 2017: sec. 5). In particular, the CJT can be

\footnotetext{
${ }^{3}$ Actually, the Condorcet Jury Theorem, named after the French mathematician and politician Marie Jean Antoine Nicolas de Caritat, Marquis of Condorcet, comprises more results than this one. I have reported only the most relevant one. Condorcet's own account of the theorem (Condorcet 1785: 119-136 and 287296) is notoriously difficult, because it is interwoven into his exposition of pairwise majority voting, a method for voting between more than two alternatives (candidates). For the mathematical details, see Goodin and Spiekermann (2018: Ch. 2).
} 
applied even if voters are influenced to some degree by an opinion leader (Grofman et al. 1983: 273-274) or if they consider the same evidence and discuss it among themselves (Dietrich and List 2004: 186-187; Dietrich and Spiekermann 2013a: 97-98, 2013b: 671-674; Goodin and Spiekermann 2018: Ch. 5). Moreover, it has been shown that the CJT can be extended to voters whose competence is heterogeneous as long as they are on average more than 0.5 likely to identify the correct alternative (Grofman et al. 1983: 269; Goodin and Spiekermann 2018: 23-25).

Finally, the CJT can also be generalized to choices between more than two alternatives if the majority rule is replaced by other voting rules. The easiest one is the plurality rule, according to which the option receiving most votes wins the election. In this case, voters are regarded as competent if and only if they are more likely to opt for the correct alternative than for any other (List and Goodin 2001: 283-288; Goodin and Spiekermann 2018: 26-31). The plurality rule is typically applied in elections of constituency representatives and poses problems of its own; for example, it sometimes leads to electoral victory of a candidate whom the majority of voters consider the worst (Dummett 1997: 5152). Hence, epistemic democrats have discussed other social choice rules such as Borda count or pairwise majority voting, which are designed to overcome some of these problems (Young 1988, 1995; List 2013; Pivato 2013).

Most legislatures of Western democracies typically use the majority rule. For example, bills need more than half the votes in order to be passed. For reasons I explain at the end of the section, I will, for the most part, focus on such binary decisions of legislatures. But the majority rule raises another problem: the number of incorrect alternatives usually exceeds the number of correct ones (even if we assume that several alternatives are equally correct). One might wonder whether the correct alternatives are ever indeed brought forward to be voted upon. Goodin and Spiekermann circumvent this problem by stipulating that political decisions are correct if they select the best option among the available alternatives on the agenda:

Suppose that the truth to be tracked within the CJT framework is the truth about which of the alternatives is 'better' than the others on the agenda. ... In that case, the object of the CJT exercise is not really one of finding the needle in the haystack of the 'one truly correct option out there in the world'. Rather, the object of the exercise is then to select the best alternative among the alternatives offered for choice. Hence, even if the very best option is not among the set of alternatives offered to voters, that in no way undermines the CJT claim, reformulated to say that the majority is highly likely to choose the best alternative among those under consideration. (Goodin and Spiekermann 2018: 44)

Thus, for a political decision to be correct, it need not be correct in every detail; it suffices to be better overall than the alternatives on the agenda. This condition seems to be met easily by members of a parliament or any other legislature. When they are to decide whether to approve a bill, they are usually instructed by experts, and some members specialize in the relevant issue. Hence, one might expect that they are, on average, more than 0.5 likely to choose the correct alternative. 
To illustrate with a simple example, suppose 100 voters are, on average, 0.55 likely to identify the correct alternative. If the other conditions for the application of the CJT are met, the probability that the majority will vote for the correct alternative is about 0.85 . The likelihood rises quickly with the number of voters. For 600 voters with the same competence, the probability that the majority will vote correctly is greater than 0.99 (Goodin and Spiekermann 2018: 22). These numbers are indeed encouraging, since the CJT seems to demonstrate that the votes of parliaments, which usually have several hundred seats, are almost certainly correct.

Many authors take the results provided by the CJT 'as powerful evidence of the truth-tracking merits of majority rule' (List and Goodin 2001: 283; cf. Barry 1964: 12-13; Cohen 1986: 34-35; Grofman and Feld 1988: 569-571; Thompson 2013: 1235-1239). Goodin and Spiekermann in particular do not only argue for the uncontroversial claim that democracy has a high chance of reaching correct decisions if all conditions for the application of the CJT are met, but they take pains to demonstrate that these conditions are often met in democracies: 'we offer those extensions and elaborations of the CJT not so much defensively as positively - as a way of helping to extend the applicability of the CJT to political life in the real world in certain genuinely important respects' (Goodin and Spiekermann 2018: 4). So, the authors do not retreat to ideal theory, but rather contend that, despite all the shortcomings of democratic decision-making, the conditions for the application of the CJT are actually met in many democratic decisions in the real world (Goodin and Spiekermann 2018: 322, cf. 301 and 314).

This claim, they believe, is in particular true for the decisions of representative democracies. Votes in parliaments and other legislatures have the disadvantage that their members often vote along party lines, which casts doubt on the assumption that they vote both independently of one another and sincerely for what they believe to be correct. On the other hand, this disadvantage may be outweighed by the fact that representatives usually have much more resources for improving their competence than average citizens. For example, they regularly engage in extensive deliberation and collaborative search before they pass laws (Grim et al. 2020), and as party members they benefit from their party's institutional and procedural mechanisms that inform their opinions and enhance their knowledge (Ebeling 2016, 2017: Ch. 6). For this reason, Goodin and Spiekermann (2018: Ch. 16) favour representative over direct democracy. In this article, I will likewise focus on the decisions of representatives who are members of parliaments and other legislatures. When I write about 'voters' without qualification, I usually refer to representatives, but similar considerations apply to ordinary voters.

\section{The first horn of the metaethical dilemma: moral realism}

One salient condition for the application of the CJT is that voters are competent. According to the relaxed version of the CJT, not all voters need to be competent, but in binary choices they have to be, on average, more than 0.5 likely to identify the correct alternative. One might dismiss this condition for the simple reason that political decisions cannot be correct (or incorrect) at all. As Schwartzberg (2015: 
199) puts it, 'democracy must be largely occupied with questions that are not plausibly truth-apt' (for a similar view, see Miller 1992: 56). In response, Goodin and Spiekermann suggest that some version of moral realism may be employed. They define moral realism broadly as the view that

there are indeed facts about what is morally of value, and these facts extend to the realm of politics. On that line of analysis, political value judgements can be true or false, and there are facts in the world that make them true or false. (Goodin and Spiekermann 2018: 38)

The idea is that a value judgement is true if it describes the moral facts accurately or if moral facts make the judgement true. To be sure, the main job of representatives is not to form value judgements but to decide about laws and regulations. But we may assume that a political decision is correct if the value judgement recommending this decision is true. Then moral realism indeed helps explain how decisions can be correct.

In political practice, the realms of moral facts and empirical facts are not so strictly separated as the above discussion suggests. ${ }^{4}$ Decision makers often have to consider both moral and empirical facts at same time. For example, when they ask themselves how to respond to climate change, to a pandemic, or to a financial crisis, they have to deal with questions that lie at the interface between morality and scientific expertise. Finding optimal solutions to such questions involves subtle trade-offs between facts about what is morally of value and the constraints imposed by reality. ${ }^{5}$ Arguably, this exceeds the capacity of any single person operating in isolation, because one has to get both the moral and empirical facts right. But if politicians pool their expertise and take the advice of experts and other citizens, their chances of figuring out the correct alternatives will usually increase significantly. So, the arguments of epistemic democracy seem to have the most traction for questions and decisions at the interface between morality and scientific expertise.

Nevertheless, in order to apply the CJT to political decisions, we have to suppose that voters are, on average, more than 0.5 likely to identify the correct alternative. Epistemic democrats do not really give reasons for the assumption that voters meet this criterion, despite objections from critics (Gaus 1997: 150-151; Estlund 2008: 228-236). Instead, Goodin and Spiekermann stress that the competence condition is modest: voters only need to be a bit better than random at figuring out the correct alternative. They just have to do minimally better than someone who chooses, say, by tossing a coin:

If people have absolutely no information or inclinations whatsoever, their votes will be random. It is easy to see how people, on average, might be a bit better

\footnotetext{
${ }^{4}$ In this paragraph, I borrow from the astute suggestions of an anonymous reviewer.

${ }^{5}$ In this respect, legislators can be compared with architects, who have to consider and make trade-offs between aesthetic values and engineering constraints. Aristotle compares legislators and architects (housebuilders) in a fragment cited by Iamblichus in Protrepticus 10, 54.12-56.2 (cf. Ober 2013: 107). See also his Nicomachean Ethics, 7.11, 1152 b1.
} 
than random - and that is all the CJT requires ... Maybe they are interested in the matter, or maybe they incidentally acquired information bearing on the matter in the course of their other activities, for example. It is hard to see how people, in general, would be worse than random. (Goodin and Spiekermann 2018: 9)

Yet contrary to what they claim, it is not so hard to see how voters might be 'dumber than a coin flip' (Estlund 2008: 18). Many political convictions are linked together. If voters are afflicted by systematic biases and prejudices such as racism or sexism, their decisions on the respective political matters could well be worse than random (Estlund 2008: 18). Interests, anxiety, and a preoccupation with their own affairs are also likely to distort their judgement (Rawls 1999: 110). Note that incompetence has disastrous effects: other things being equal, if the voters' beliefs about the correct alternative are, on average, less than 0.5 likely to be true, the probability of a majority of voters reaching a correct decision converges to 0 as the number of voters rises. This effect has been described as the 'reverse Condorcet jury theorem' (List and Pettit 2011: 98).

Goodin and Spiekermann (2018: 238-239) do not deny that biases and prejudices undermine voter competence, but they hope that democracies have an inbuilt tendency to reduce the influence of biases and prejudices, because democracy extends the franchise to all adult citizens and increases diversity among voters. However, this response is not particularly satisfying. Empirical data from the USA suggest that in recent decades biases have become more widespread and stronger (for a review of recent findings, see Brennan 2017: Chs. $2-3)$. This fact would not pose a problem if roughly the same number of voters were biased in different directions, so that their biases cancel each other out. Whether or not that is the case, would have to be determined in each instance by empirical research - which, however, would exceed the scope of this article. Hence, I refrain from enlarging on the problem of biases and prejudices. Instead, I seize on an earlier proposal from Goodin and Estlund. After admitting that 'the question of whether voters are on average better than random is not easily decidable when approached head-on', they suggest going roundabout: 'Instead of trying to decide whether or not voters are better than random, in general, let us use the outcome of the election to help us reflect on judgments about average voter competence' (Goodin and Estlund 2004: 133). I think this approach will lead to an awkward conclusion for epistemic democracy.

Moral realists claim that value judgements are true if they describe moral facts accurately or if they are made true by moral facts. Moreover, moral facts and moral truths are considered to be response-independent, that is, they are considered to exist independently of people's intentional attitudes such as beliefs, preferences, desires, commitments, perspectives, or points of view (Shafer-Landau and Cuneo 2007: 157-158; cf. Sayre-McCord 2021). For example, moral realists maintain that if gender-based discrimination is wrong, this practice is wrong in every society, even in a society in which everyone believes it to be permissible or approves of it (Enoch 2021: 208-209). So, the following two metaphysical implications shall be uncontroversial among them: (1) moral facts do not change constantly, and (2) they do not differ from country to country, or from society 
to society. Accordingly, under the assumption of moral realism a striking congruence of democratic decisions is to be expected if the conditions for the application of the CJT are met.

In actual fact, majority views on most political issues are subject to constant change, which is well recorded by opinion polls and changing election outcomes. When the majority view of the voters changes, the majority view of the elected members of legislatures usually changes as well. What is more, different democratic legislatures reach contrary decisions at the same time; for example, some parliaments have been introducing laws legalizing same-sex marriage, active euthanasia, and certain drugs, while other parliaments have refused to.

Admittedly, Western democracies agree on many issues: they have introduced various civil liberties such as the freedom of conscience, religion, and speech; slavery was abolished, and discrimination against minorities prohibited. We have good reasons to consider these decisions to be correct (Ingham 2012: 147-148). However, civil liberties and rights are still subject to controversy. Contemporary democracies discuss both the content and reach of them, and constitutional and supreme courts frequently have to determine their meaning. Apart from that, most issues that actually have to be decided upon concern economic and social policies such as the distribution of wealth or the regulation of markets, which are 'commonly subject to reasonable differences of opinion' (Rawls 1999: 174); even eminent philosophers and economists persistently disagree over these issues. These are also the issues on which different legislatures frequently come to very divergent decisions at the same time.

Now, the following inference can be made: if, under the assumption of moral realism, the conditions for the application of the CJT are met, we will observe a striking congruence of democratic decisions. But that is not the case, given the wide variation in the political decisions that are actually made in democracies. It follows that the conditions for the application of the CJT are not met under the assumption of moral realism; either the representatives are, on average, not better than random at tracking moral facts and identifying the correct alternative, or some other condition is violated.

To be sure, I do not deny that in certain countries the members of legislatures are, on average, better than random at tracking moral facts. Nor do I deny that on certain subjects most politicians at all times and places vote for the correct alternative. Rather, the above argument from international disagreement ${ }^{6}$ targets epistemic democracy's general claim that real-world democracies have a high chance of reaching correct decisions. If we adopt moral realism, we cannot apply the CJT in order to derive a general claim about the epistemic performance of democracies.

\section{Grasping the first horn of the metaethical dilemma?}

One may grasp the first horn of the dilemma in several ways. I will discuss five objections against my claim that moral realism is detrimental to a CJT-based defence of democracy.

${ }^{6}$ I owe this label to an anonymous reviewer. 
First, epistemic democrats could retreat from the strong claim that democracy is a reliable truth-tracker regularly arriving at the correct answer, but instead confine themselves to the weaker claim that democracy has a higher probability of so arriving than any other form of government (this claim is also made by epistemic democrats, cf. Goodin and Spiekermann 2018: 301 and 314). To corroborate it, they could allege that there is significantly more disagreement (and armed conflict) between non-democratic systems. Also among nondemocratic regimes of the same type, such as dictatorships or theocracies, there are more policy differences than among democracies. If it turns out that there is less disagreement among democracies than in non-democracies, one could take that as evidence undermining the argument from international disagreement. ${ }^{7}$

I admit that there is usually more convergence among democracies than among non-democracies. However, democratic decisions do not exhibit that wide congruence which would have to be expected under the assumption of moral realism if the conditions for the application of the CJT were met. The diachronic changes in majority views and the synchronic diversity among different legislatures are incompatible with moral realism's creed that moral facts neither change nor differ from one community to another. Hence, one has to abandon either moral realism or refrain from employing the CJT in order to defend any claims about the reliability of democracy. This applies, I think, also to the weak claim that democracies have a higher chance of reaching correct decisions than other regimes.

Second, one may point out that the argument from international disagreement has little philosophical significance. It merely exposes that, for the time being, the conditions for the application of the CJT are not met under the assumption of moral realism. But democracies are still relatively young in comparison to most other forms of government. Suppose the divergence in democratic decisions is only a temporary phenomenon that will be overcome when democracies mature. Then my argument does not demonstrate that a CJT-based defence of democracy cannot rest on moral realism. In fact, we can observe some moral progress. In the long run, the objection continues, democratic decisions tend to converge towards the correct ones. Same-sex marriage seems to be a good example. At the moment, it is legal in relatively few countries, but the number is growing; and no parliament has ever abolished its own prior legalization on this. If we suppose that it is correct to legalize same-sex marriage, we can assume that parliaments are making progress on that matter, and so are their members. We may conjecture that the politicians' competence is rising also in other decisions, with the result that they will eventually become, on average, more than 0.5 likely to identify the correct alternatives.

Note, however, that this line of argument makes two controversial assumptions: first, that there is some long-run convergence of democratic decisions; and second, that the respective decisions are indeed correct. Both assumptions are controversial. The first assumption is an empirical claim that is difficult to verify. There is indeed anecdotal evidence for convergence on some political issues, and same-sex marriage is a case in point. But it is a special case: the right to marry a person of the same sex is considered to be a civil right that is or was denied for arbitrary reasons. (In some

\footnotetext{
${ }^{7}$ This objection was raised by an anonymous reviewer.
} 
states, it was constitutional or supreme courts that prompted its legalization.) It is much more difficult to spot convergence of democratic legislation in the realm of economic and social policies. Sure, Western democracies rarely opt for extreme policies such as the implementation of a full-blown socialist economy or a perfectly free market economy. But they decide very differently on a variety of matters such as the regulation of markets or the amount of welfare spending. And in most countries the pendulum regularly swings from one policy to another when governments are replaced as a result of elections.

Even if some evidence of convergence in democratic decisions is available, it is still an open question whether the second assumption is true, according to which the respective decisions are correct. From the mere fact that most legislatures converge on some issues, we must not conclude that the decisions are correct. Take, for example, one major convergence of the last decade: the rise of populism and nationalism. In the wake of this development, many Western states have decided to restrict immigration and the right of asylum, and they have introduced more protectionism. But it is doubtful whether these decisions are correct. Most political philosophers presumably do not approve of them and would rather regard them as symptoms of moral decline.

In a long epilogue, Goodin and Spiekermann (2018: Ch. 21) argue that Donald Trump's victory in the 2016 US presidential election and the UK's majority decision for Brexit at the 2016 EU referendum can both be accounted for by the fact that central conditions for epistemically effective decision-making were neglected. For example, politicians and social media spread numerous lies before these ballots. In such cases, the CJT cannot be applied. That is true, yet Trump's victory and the vote for Brexit cannot be conceived as rare accidents. They were rather part of a longstanding trend that resulted in victories for populist parties and policies all around the world; and despite Trump's narrow defeat in the 2020 election, the trend seems to persist. I conclude that we cannot suppose that democratic decisions progress towards correctness, since, on the one hand, it is difficult to spot convergence of political decisions; and, on the other hand, when there is some convergence, it is often doubtful whether the respective decisions are correct.

In the previous section, I asserted that one metaphysical implication of moral realism is that moral facts do not differ from country to country. The third, and arguably the strongest, objection denies this implication by arguing that moral realism is compatible with the assumption that moral facts differ from country to country (a similar objection is raised and rejected in Mackie 1977: 37-38). Alternatively, one might assume that moral facts, though universally valid, are sensitive to relevant features of different countries such as their political culture or their economic circumstances. These claims could be justified by an analogy: some moral philosophers believe that certain kinds of actions are morally required or permitted only in particular situations. To take a well-known example, it is usually not permitted to lie, but in certain situations, such as someone's life being under threat, it might be permitted or even required to lie if that is the only available way to avoid greater harm (Mill 1871: 33-34). One might argue that political decisions also have to be adjusted to the political culture and economy of a country; since culture and economy vary from country to country, the moral facts vary, too. 
Suppose, for example, a country is not 'ready' for same-sex marriage, and legalizing it 'too soon can have bad effects for stability, or give rise to devastating backlashes' ${ }^{8}$ Arguably, it might be incorrect to legalize it in those circumstances, whereas the same decision might be correct for other countries whose citizens are more open to homosexuality. In this way, one might attempt to explain why different legislatures reach contrary, and yet correct, decisions. Note that this objection does not presuppose that the background culture and related values and norms are themselves correct; such an assumption would come close to moral conventionalism, which will be addressed in the next section. Rather, the objection presumes that the cultural conditions must be considered as facts that might bear on whether a political decision is correct or not.

I do not reject this latter claim. Several ethical and political theories committed to moral realism acknowledge that the correct decision depends on certain cultural factors (in the broadest sense). For example, a standard version of utilitarianism claims that an action or rule is correct if and only if it obtains the greatest sum of satisfaction of people's preferences and interests (I ignore the distinctions between various forms of utilitarianism, as they do not matter here). If people's preferences and interests differ significantly from one country to another, it is, in principle, possible that different political decisions should prove to be correct according to utilitarianism. For instance, countries with many deeply religious citizens might be right in providing more financial support to churches than secular countries. Similarly, the utilitarian Peter Singer concedes that the issue of admitting refugees is one to which the facts - for example, about the possibility of a country taking in large numbers of refugees without this leading to a racist backlash that would harm minority groups within the country - are highly relevant' (Singer 2011: xi).

However, utilitarians usually do not infer contrary conclusions for different countries when they approach momentous political issues such as same-sex marriage (Singer 2006), abortion (Singer 2011: Ch. 6), euthanasia (Singer 2011: Ch. 7), immigration (Goodin 1992), nuclear weapons and disarmament (Goodin 1995: Ch. 17). The preferences and interests of those who are immediately affected by the laws regulating these issues are so great, and their dissatisfaction would be so harmful, that they usually cannot be outweighed by other persons' preferences and interests. That is part of the reason why utilitarians discussing these matters rarely differentiate between countries and do not reach diametrically opposed conclusions for them. And nor do other moral realists, such as social contract theorists. However, the issues mentioned above are the ones where countries differ widely in their policies. So, differences in cultural factors, values, norms, preferences and interests do not help explain how contrary policies might be correct at the same time.

It may be somewhat easier to explain differences in economic and social policy. On the one hand, citizens differ in their preferences concerning social security and welfare; on the other hand, the countries themselves often differ enormously in economic and social structure. Arguably, for a wealthy country faced with economic stagnation, it can be correct to raise public spending in order to

${ }^{8} \mathrm{I}$ owe the quoted example to an anonymous reviewer. 
increase the demand for goods and services, while the same decision would be incorrect for a heavily indebted country.

However, differences in economic and social indicators can only partly account for the huge differences in actual policy. To illustrate this point, suppose the members of the UK parliament were to take over the seats of the US congress for some years and vice versa. ${ }^{9}$ Let us assume that the politicians have lived in the other country for a considerable time and have become acquainted with its political culture and institutions. Further assume that the politicians and their families were to settle permanently in the other country, so that they would have to bear the consequences of their decisions. I conjecture that the politicians would make tremendous changes to the policies of their new countries: for example, the UK politicians, if not stopped by a presidential veto, would probably increase the US's expenditure on social protection, health care, and education, while they would cut military spending, abolish school prayers, and reduce the sentences for most crimes.

Certainly, Labour politicians would tend to more radical departures from previous US policy than Conservative politicians, but it is clear that the decisions of UK politicians would in any case differ sharply from the decisions of their US colleagues, who, after taking over the UK parliament, would change the terms of UK policy in the opposite direction. Note that the political cultures of the US and UK are relatively similar. Had we invited, say, the members of the Swedish parliament to exchange seats with their US colleagues, they would certainly launch much more radical political changes. The outcome of my thought experiment suggests that most differences in political decisions cannot be explained by reference to differences in the countries' economic and social circumstances alone.

In conclusion, the assumption that moral facts differ from country to country, or that moral facts are sensitive to relevant features of different countries, has little explanatory power. I do not want to claim that it is impossible to develop some form of moral realism that is hypersensitive to local cultural and economic conditions and therefore justifies contrary policies for different polities. For instance, some forms of moral particularism qualify as moral realism, as they acknowledge moral facts; at the same time, they claim that moral facts always depend on the circumstances of each situation and deny the existence of general moral principles (Dancy 2004: Ch. 8). However, at least Goodin and Spiekermann cannot retreat to such a position, because, first, the common varieties of moral realism such as utilitarianism (Goodin's preferred theory) leave little room for such a move and, second, that would undermine their claim that epistemic democracy is compatible with, and can be based on, a broad range of metaethical views.

The fourth objection is closely related to the latter one. It, too, targets the assumption from section 3 that moral facts do not differ from country to country. One might argue that wide acceptance of laws and regulations is valuable. The fact that many people will probably have a positive attitude toward a proposed law provides a moral reason to adopt it. By contrast, 'the fact that

${ }^{9}$ This thought experiment was suggested to me by Marco Hausmann. 
some law is not widely accepted (or is not likely to become widely accepted in the future) is a moral reason for politicians to support laws they deem a moral secondbest on the first level of moral evaluation' (Wendt 2018: 59). This consideration distinguishes two levels of moral evaluation: on the first level, the acceptance of proposed laws is ignored. On the second level, the extent to which proposed laws are accepted is considered as a fact that might have a bearing on which decision is correct, all things considered. Since the acceptance of laws varies from country to country, one might assume that moral facts vary, too.

Note that this objection does not presuppose that wide acceptance provides a conclusive moral reason to adopt a law; such an assumption would come close to moral majoritarianism, which will be addressed in the next section. Rather, the objection assumes that wide acceptance provides a (pro tanto) moral reason that can be outweighed by other moral reasons. In particular, bad or unjust laws cannot be defended as correct even if they are widely accepted (Wendt 2018: 56). As a consequence, the fact that the citizens' attitudes vary from country to country explains only minor differences in laws. By contrast, if one country legalizes, say, active euthanasia while another one penalizes it, one of them has apparently adopted a bad or unjust law. In this case, wide acceptance cannot render the decision correct. The same holds for numerous other controversial issues such as abortion, capital punishment, same-sex marriage, or nuclear disarmament, where democracies have opted for diametrically opposed policies. We cannot but assume that these issues are governed by bad or unjust laws in some democracies. So, the assumption that wide acceptance of laws provides a moral reason to adopt them does not help explain how widely different policies might be correct at the same time.

One might finally object that I have depicted politicians too much as idealists who try to impose their moral and political values without minding their political careers. Most politicians seek re-election and thus adjust their decisions to the prevalent values and views of prospective voters, even if they would personally prefer different decisions; otherwise, they risk being voted out. Note, however, that in this case the politicians do not purport to track moral facts. Either they do not vote sincerely for what they believe to be the correct alternative; as mentioned in section 2, such strategic voting violates one of the conditions for the application of the CJT. Or they really believe that their decision is correct given the prevalent values or majorities of their country; in this case, they employ an account of correctness that corresponds to moral conventionalism or moral majoritarianism. This brings us to the second horn of the metaethical dilemma.

\section{The second horn of the metaethical dilemma: moral conventionalism and moral majoritarianism}

In this section, I show that epistemic democrats do not fare better if they switch to non-realist metaethics, in particular to the ones brought into play by Goodin and Spiekermann: moral conventionalism and moral majoritarianism. Conventionalism states that moral values and norms are socially invented or constructed by the community: 
On that account, values are social constructs, which vary from one place to another. ... There is, on this account, some fact of the matter about what are the moral norms that are in force 'around here'. Those facts are, on this account, constituted by what people generally take a critical reflective attitude towards, of a distinctively moral sort, within the community in question. (Goodin and Spiekermann 2018: 40)

According to this view, which some ethicists describe as cultural relativism (ShaferLandau 2021: 317), a political decision is correct if the prevalent moral values and norms of a given community recommend it. Conventionalism demands a rather broad consensus on moral values and norms to make them a criterion for the correctness of political decisions. By contrast, majoritarianism supposes that political decisions are correct if they are correct from the majority's point of view:

[D]ifferent people have different values within the community, and different answers are 'correct' from each of those different perspectives.

Even in that case, insofar as one of those alternatives has to be socially adopted for the community as a whole, it is democratically desirable to choose the one that is correct from the point of view of the larger segment of the community (subject of course to substantive constraints designed to prevent the majority from becoming tyrannical). (Goodin and Spiekermann 2018: 41)

It is worth noting that, like moral realism, conventionalism and majoritarianism provide a procedure-independent standard of correctness for political decisions. According to them, political decisions can be objectively correct or incorrect: it is objectively the case that, within a particular society, specific moral values/ norms prevail, and it is also an objective matter of fact that the majority approves of specific decisions. At the same time, it seems that both accounts set less demanding standards of competence than moral realism.

As for conventionalism, representatives are required to be better than random at identifying the prevalent values and norms of their community and figuring out what they recommend. Since representatives regularly deliberate on values and norms and are often advised by social scientists and other experts, it seems quite possible that they are sufficiently competent. A similar conclusion may be drawn with respect to majoritarianism. Miller (1986: 177-183) and also List and Spiekermann (2016) present CJT-based arguments that build upon majoritarianism. They discuss only decisions in which the whole electorate is invited to cast a vote. In these cases, the competence condition requires that, on average, each voter is better than random at identifying the alternative which is correct from the voter's own point of view (in Miller's terms, this is the alternative that best serves the voter's interests). To apply majoritarianism to representatives, we have to assume that they are better than random at identifying the alternative which is correct from the point of view of the larger segment of the community. That is not a high hurdle in most instances. In Western democracies, the people's voice is constantly monitored by numerous opinion polls; so, representatives are usually quite well informed about what the 
majority prefers. This may give grounds for optimism about the applicability of the CJT to political decisions. ${ }^{10}$

But do representatives vote in conformity with the prevalent values and norms of their community, or in conformity with poll results? Some indeed attempt to support laws and policies that are recommended by the prevalent values and norms. Others decide on the basis of their beliefs about what the majority prefers; this is especially true for representatives who see themselves mainly as delegates of their constituents (Goodin and Spiekermann 2018: 254-259). But many others opt for what they believe to be in the national interest or in the common good (for empirical data on the large extent of sociotropic economic voting in favour of economic growth, see Berger and Sales 2020: 27-30). Still others vote for what they regard as correct from their own perspective, maybe following their conscience (some constitutions explicitly require deputies to follow only their conscience). Finally, there are all those who simply vote along party lines, out of loyalty to their party or in order to avoid conflicts with other members. This list of different voting motivations is, of course, not exhaustive, but it will suffice to illustrate the 'mixed-motivation problem' (Wolff 1994), which makes it difficult to base epistemic democracy on conventionalism or majoritarianism.

A decision of a representative body can be considered to represent the prevalent values and norms of the community only if most members actually aim at supporting laws and policies recommended by these values and norms. But the latter assumption is probably wrong, because most representatives have other motivations for voting the way they do. It is indeed possible that some of them happen to vote according to the prevalent values and norms; someone who, say, follows their conscience may occasionally vote for an alternative that is also recommended by the prevalent values and norms of their community. But such coincidences are probably rare. So, from the standpoint of conventionalism, it is doubtful that representatives are both competent and sincere, because they are either not more that 0.5 likely to identify the correct alternatives, namely the alternatives recommended by the prevalent values and norms, or they are not motivated to vote for these alternatives. Either way, conventionalism does not entitle us to apply the CJT in order to draw general conclusions about the correctness of democratic decisions.

The same holds for majoritarianism: because many representatives do not vote on the basis of their beliefs about what the majority prefers, we cannot assume that their decisions represent the view of the larger segment of the community. So, also from the standpoint of majoritarianism, it is doubtful that both the competence condition and the sincerity condition are met. As a consequence, neither

\footnotetext{
${ }^{10}$ Of course, this optimism is justified only if opinion polls meet certain methodological standards. Moreover, the respondents have to answer the questions sincerely. Finally, the competence to identify the alternative which is correct from one's own point of view has to be roughly equal across alternatives. That is, if people are to decide between two alternatives A and B, those whose interests are best served by A must have roughly the same chance to realize that as those with a true interest in $\mathrm{B}$ (List and Spiekermann 2016: 226-228).
} 
conventionalism nor majoritarianism help to establish the claim that democratic decisions are likely to be correct. ${ }^{11}$

Aside from the mixed-motivation problem, both conventionalism and majoritarianism are cursed with problems of their own, which I cannot discuss in detail here. But I should mention that one problem becomes particularly virulent when conventionalism or majoritarianism is taken as a metaethical framework for thinking about politics. I will address conventionalism and majoritarianism simultaneously, presenting the claims of majoritarianism in square brackets: if we adopt either account, we have little reason to criticize democratic decisions; for instance, when same-sex marriage contravenes the values and norms of the community [when the majority of a country's citizens disapproves of same-sex marriage], proponents of conventionalism [majoritarianism] have to regard the legal prohibition of same-sex marriage as the correct decision - even if they personally approve of same-sex marriage. Likewise, they have to concede that its prohibition is correct even if they themselves live in a polity whose values and norms [whose majority] approve of same-sex marriage; in this case, conventionalists [majoritarianists] may claim that a prohibition of same-sex marriage would be wrong within their own polity, but the values and norms [views] in their own community become irrelevant when they assess another community's decision.

The problem is that there is no room left for criticism after a political decision has been declared to be correct. It would be odd to criticize a decision one regards as correct. So, conventionalism [majoritarianism] will undercut criticism of decisions that are recommended by the prevalent values and norms of the community [decisions that are correct from the majority's point of view]. Conventionalism [majoritarianism] allows only for internal criticism, that is to say, claims that a decision is incorrect because the prevalent values and norms recommend against it [because it contravenes the majority's point of view]. Internal criticism can indeed be effective in some situations. For example, it can be expressed when a former democratic decision does not reflect the current community's prevalent values and norms [the current majority's point of view] any more. However, internal criticism is not what political theorists, philosophers, and critics usually aim at when they condemn a policy as incorrect, wrong, or unjust.

\section{Conclusion}

Aggregative approaches to epistemic democracy based on the CJT are faced with a metaethical dilemma: on the one hand, moral realism seems to be the natural companion to epistemic democracy. However, majority views on most political issues are subject to constant change, and different legislatures reach contrary

\footnotetext{
${ }^{11}$ Does the mixed-motivation problem arise also when epistemic democracy is based on moral realism? As mentioned above, some representatives support laws that are recommended by the prevalent values and norms of their community, while others decide on the basis of their beliefs about what the majority prefers. In these cases, they apparently do not base their decisions on response-independent moral facts. That casts further doubt on the assumption that representatives are, on average, more than 0.5 likely to opt for the correct alternative.
} 
decisions at the same time. Hence, it is doubtful that representatives are, on average, more than 0.5 likely to track moral facts and identify the correct alternative. On the other hand, epistemic democracy does not fare better with non-realist metaethics such as conventionalism or majoritarianism. Because representatives have different motivations for voting the way they do, we cannot expect that they are both competent and sincere. Whichever metaethical account we adopt, the conditions for the application of the CJT are not met, and so the CJT-based argument for the reliability of democratic decision procedures does not get off the ground.

Although I have focused in this article on the CJT, which is usually applied to binary choices made by majority vote, I should stress that the metaethical dilemma of epistemic democracy arises also when we turn to choices between more than two alternatives. Epistemic democrats have suggested several voting rules for such choices (section 2). However, an epistemic interpretation of these rules, according to which they are likely to pick out the correct options, imposes conditions similar to the CJT; that is, voters have to be competent, independent, and sincere (Young 1988). Borda count and pairwise majority voting make even greater demands on competence than majority rule and plurality rule, because they require voters to rank the options. So, my objections against the applicability of the CJT work against these rules, too.

I do not want to suggest that there is no way to resolve the metaethical dilemma. My article is not intended to deliver a final blow against epistemic theories of democracy, but rather to express a plea that their proponents should explicate and fix their metaethical basis. Epistemic democrats could either give a new interpretation of one of the metaethical accounts discussed in this article or proffer another metaethical account. They could perhaps advocate some form of moral realism which is hypersensitive to local cultural and economic conditions and thus justifies contrary policies for different polities. However, using this loophole means giving up the claim that epistemic democracy is compatible with, and can be based on, a broad range of metaethical views.

Acknowledgements. For helpful discussions and critical comments on earlier versions of this paper, I would like to thank Martina Funkett, Marco Hausmann, Geert Keil, Olaf Müller, Nora Olbrisch, Kai Spiekermann, Andree Weber and Ben Young. I am extremely grateful for the suggestions of the anonymous reviewers, who raised interesting objections and helped me clarify the paper in many places. The research was generously supported by the Volkswagen Foundation as part of the research group Deep Disagreements at Humboldt University of Berlin and Albert Ludwig University of Freiburg.

\section{References}

Anderson E. 2006. The epistemology of democracy. Episteme 3, 8-22.

Barry B.M. 1964. The public interest. Proceedings of the Aristotelian Society, Supplementary Volumes 38, $1-18$.

Berger W.J. and A. Sales 2020. Testing epistemic democracy's claims for majority rule. Politics, Philosophy \& Economics 19, 22-35.

Black D. 1958. The Theory of Committees and Elections. Cambridge: Cambridge University Press.

Brennan J. 2017. Against Democracy. Princeton, NJ: Princeton University Press.

Bright L.K. 2019. Book review of An Epistemic Theory of Democracy, R.E. Goodin and K. Spiekermann. Economics and Philosophy 35, 563-568. 
Cohen J. 1986. An epistemic conception of democracy. Ethics 97, 26-38.

Condorcet M. 1785. Essai sur l'application de l'analyse à la probabilité des décisions rendues à la pluralité des voix. Paris: Imprimerie royale.

Dancy J. 2004. Ethics Without Principles. Oxford: Clarendon Press.

Dietrich F. and C. List 2004. A model of jury decisions where all jurors have the same evidence. Synthese 142, 175-202.

Dietrich F. and K. Spiekermann 2013a. Epistemic democracy with defensible premises. Economics and Philosophy 29, 87-120.

Dietrich F. and K. Spiekermann 2013b. Independent opinions? On the causal foundations of belief formation and jury theorems. Mind 122, 655-685.

Dummett M. 1997. Principles of Electoral Reform. Oxford: Oxford University Press.

Ebeling M. 2016. Epistemic political egalitarianism, political parties, and conciliatory democracy. Political Theory 44, 629-656.

Ebeling M. 2017. Conciliatory Democracy: From Deliberation Toward a New Politics of Disagreement. London: Palgrave Macmillan.

Enoch D. 2021. Why I am an objectivist about ethics (and why you are, too). In The Ethical Life: Fundamental Readings in Ethics and Moral Problems, ed. R. Shafer-Landau, 203-216. New York, NY: Oxford University Press.

Estlund D. 1993. Making truth safe for democracy. In The Idea of Democracy, ed. D. Copp, J. Hampton and J.E. Roemer, 71-100. New York, NY: Cambridge University Press.

Estlund D. 2008. Democratic Authority: A Philosophical Framework. Princeton, NJ: Princeton University Press.

Estlund D. 2012. The truth in political liberalism. In Truth and Democracy, ed. J. Elkins and A. Norris, 251-271. Philadelphia, PA: University of Pennsylvania Press.

Estlund D. and H. Landemore 2018. The epistemic value of democratic deliberation. In The Oxford Handbook of Deliberative Democracy, ed. A. Bächtiger, J.S. Dryzek, J. Mansbridge and M. Warren, 113-131. Oxford: Oxford University Press.

Gaus G. 1997. Does democracy reveal the will of the people? Four takes on Rousseau. Australasian Journal of Philosophy 75, 141-162.

Goodin R.E. 1992. If people were money. In Free Movement, ed. B. Barry and R.E. Goodin, 6-22. University Park, PA: Pennsylvania State University Press.

Goodin R.E. 1995. Utilitarianism as a Public Philosophy. Cambridge: Cambridge University Press.

Goodin R.E. and D. Estlund 2004. The persuasiveness of democratic majorities. Politics, Philosophy \& Economics 3, 131-142.

Goodin R.E. and K. Spiekermann 2018. An Epistemic Theory of Democracy. Oxford: Oxford University Press.

Grim P., A. Bramson, D.J. Singer, W.J. Berger, J. Jung and S.E. Page 2020. Representation in models of epistemic democracy. Episteme 17, 498-518.

Grofman B. 1975. A comment on 'Democratic theory: a preliminary mathematical model.' Public Choice 21, 99-103.

Grofman B. and S.L. Feld 1988. Rousseau's general will: a Condorcetian perspective. American Political Science Review 82, 567-576.

Grofman B., G. Owen and S.L. Feld 1983. Thirteen theorems in search of truth. Theory and Decision 15, 261-278.

Ingham S. 2012. Disagreement and epistemic arguments for democracy. Politics, Philosophy \& Economics 12, 136-155.

Kaniovski S. 2010. Aggregation of correlated votes and Condorcet's Jury Theorem. Theory and Decision 69, 453-468.

Ladha K.K. 1992. The Condorcet Jury Theorem, free speech, and correlated votes. American Journal of Political Science 36, 617-634.

Landemore H. 2017. Beyond the fact of disagreement? The epistemic turn in deliberative democracy. Social Epistemology 31, 277-295.

List C. 2013. Social choice theory. In Stanford Encyclopedia of Philosophy (Winter 2013 Edition), ed. E.N. Zalta. <https://plato.stanford.edu/archives/win2013/entries/social-choice/>. 
List C. and R.E. Goodin 2001. Epistemic democracy: generalizing the Condorcet Jury Theorem. Journal of Political Philosophy 9, 277-306.

List C. and P. Pettit 2011. Group Agency: The Possibility, Design, and Status of Corporate Agents. Oxford: Oxford University Press.

List C. and K. Spiekermann 2016. The Condorcet Jury Theorem and voter-specific truth. In Goldman and His Critics, ed. B.P. McLaughlin and H. Kornblith, 219-231. Hoboken, NJ: Wiley.

Mackie J.L. 1977. Ethics: Inventing Right and Wrong. London: Penguin.

Mill J.S. 1871. Utilitarianism. London: Longmans, Green, Reader, and Dyer.

Miller D. 1992. Deliberative democracy and social choice. Political Studies 40, 54-67.

Miller N.R. 1986. Information, electorates, and democracy: some extensions and interpretations of the Condorcet Jury Theorem. In Information Pooling and Group Decision Making: Proceedings of the Second University of California, Irvine, Conference on Political Economy, ed. B. Grofman and G. Owen, 173-192. Bingley: Emerald.

Ober J. 2013. Democracy's wisdom: an Aristotelian middle way for collective judgment. American Political Science Review 107, 104-122.

Pivato M. 2013. Voting rules as statistical estimators. Social Choice and Welfare 40, 581-630.

Pivato M. 2017. Epistemic democracy with correlated voters. Journal of Mathematical Economics 72, 51-69.

Rawls J. 1999. A Theory of Justice. Cambridge, MA: Harvard University Press.

Sayre-McCord G. 2021. Moral realism. in Stanford Encyclopedia of Philosophy (Summer 2021 Edition), ed. E.N. Zalta. <https://plato.stanford.edu/archives/sum2021/entries/moral-realism/>.

Schwartzberg M. 2015. Epistemic democracy and its challenges. Annual Review of Political Science 18, 187-203.

Shafer-Landau R. 2021. The Fundamentals of Ethics. New York, NY: Oxford University Press.

Shafer-Landau R. and T. Cuneo, eds. 2007. Foundations of Ethics: An Anthology. Malden, MA: Blackwell.

Singer P. 2006. Homosexuality is not immoral. <https://www.utilitarian.net/singer/by/200610-.htm>.

Singer P. 2011. Practical Ethics. Cambridge: Cambridge University Press.

Thompson C. 2013. A general model of a group search procedure, applied to epistemic democracy. Synthese 190, 1233-1252.

Wendt F. 2018. Compromise and the value of widely accepted laws. In Compromise and Disagreement in Contemporary Political Theory, ed. C.F. Rostbøll and T. Scavenius, 50-62. London: Routledge.

Wolff J. 1994. Democratic voting and the mixed-motivation problem. Analysis 54, 193-196.

Young H.P. 1988. Condorcet's theory of voting. American Political Science Review 82, 1231-1244.

Young H.P. 1995. Optimal voting rules. Journal of Economic Perspectives 9, 51-64.

Christoph Schamberger has been a postdoctoral researcher within the research group Deep Disagreements at Humboldt University of Berlin, and he teaches philosophy at the University of Erfurt. His research interests include philosophical logic, philosophy of language, social epistemology and its application to politics and political theory. URL: christoph-schamberger.name

Cite this article: Schamberger C (2023). The metaethical dilemma of epistemic democracy. Economics \& Philosophy 39, 1-19. https://doi.org/10.1017/S0266267121000328 